\title{
Unmanned aerial systems for auxiliar planning in hydrologic basin
}

\begin{abstract}
Several millions of water liters are lost around the world for a deficient management of water between source to crop field. UAD, Unmanned Aerial Devices, RemotelyPiloted Aerial Devices, also called drones are an efficient tool of increasing use in engineering and can be used in situations where a manned inspection is not possible. With the advent of low-cost equipment with sophisticated computer vision, robotics and geomatic engineering, these devices are able to generate high-resolution images and videos even with low cost cameras. Performance of hydrologic region depends on its maintenance to get functionality, operability and to ensure life expectancy, which demand frequent supervision and use of resources. Mexican hydrologic conditions are high linked at stochastic environment conditions, plus large surface implied a real difficult to basin management. Consequently, monitoring of environment factor such as, precipitation and evapotranspiration are constant activities in order to get a sustainably resources. In this work, a potential use of UADs as show, as a tool to help monitor operations and maintenance activities of Mexican hydrologic and hydraulic systems. The results indicate that UADs provide the appropriate platforms to transport remote sensor and achieve the supervision and monitoring process of hydraulic conditions in a basin. The results are opportune detection of water volume in basin, water plan delivery, of water leaks and performance of irrigation service.
\end{abstract}

Keywords: UAV, drone, monitoring and supervision system, hydrologic basin, irrigation schemes
Volume 2 Issue 4 - 2018

\author{
Jorge Flores Velazquez \\ Mexican Institute of Water Technology, Mexico
}

Correspondence: Jorge Flores Velazquez, Mexican Institute of Water Technology, Paseo Cuauhnáhuac 8532, 62550, Mexico, Email jorge_flores@tlaloc.imta.mx

Received: June 29, 2018 | Published: July 24, 2018

\section{Introduction}

Water management in Mexico, is based by 13 hydrologic basins around the country. Water is delivery at irrigation districts based in the source water volume in close to 4 000dams. Mexico has around 6.5 million hectares of irrigated agriculture which represent $25 \%$ of the cultivated surface, out of which, $50 \%$ of the value of production is obtained. From to total irrigated surface, $91 \%$ is superficial irrigation, and the rest, 560 thousand hectares, represent pressurized irrigation system. ${ }^{1,2}$ However, the limit has now been reached for the agricultural frontier because of the lack of water, for this reason it is has become necessary to increase the productivity of irrigation water and reduce the waste of water in the operation. Nowadays, technologies have been developed that will allow the efficient and rationed use of water with the purpose of facing the increasing demand of consumption. These technologies have allowed for a better control process of production, with an emphasis of the proper management of resources. This use of has been made possible in part, due to the implantation of efficient systems in several stages of the basin; beginning from the storage source, follow the net irrigation requirement for the allotment being cultivated, as well as the timely manner of its application directly in the crop field. Here we combine Hydrologic, hydraulic and agronomical factors. ${ }^{3,4}$ However, in each one of these steps, the main factor for the useful water use is the fast and trustworthy data acquisition.

In agriculture sector, the management of basin include necessarily water volume. Water volume in the basin or dams is a stochastic process, because depend of spatial and temporal precipitation process, for that, hydrologic management is too difficult. On the other hand, making the water reach the plant from the source involves a complex distribution network and derivation devices that must be in function to avoid water waste. Keeping in proper condition this network is understated as complicated, partly because of the dispersion and accessibility to the site, but also because of the lack of personnel. The technological development has been fundamental in keeping the work and systems, by including accurate instruments to maintain control. Nevertheless, when no on-line data transmission method exists, monitoring is imperative in transporting the device for visual supervision. Among the possibilities for this supervision, the use of unmanned aerial devices can be found (UAD). Because of the technical, operative and economic advantages that a UAD implies, in the last decade, several procedures for the analysis of information generated by sensors in UADs have been developed. Among the implemented techniques, the characterization of pixels stands out (un-mixing the sub-pixel) which is the feature of which the resolution of the image depends ${ }^{5}$ as well as the geometrical features. Several procedures have been used and defined to approach the analysis of information that a pixel provides. For the implementation of these models, it has been contemplated to use (Atkinson et al., 1997), artificial neural networks (ANN), modeling of the linear mixing method and classification. Other methods to value the area based on the size of the pixel include. ${ }^{6-9}$ approximations through regressions, high resolution imaging (HRI) and georeferencing or comparing parts of the land. Gallego et al., ${ }^{6} \&$ Gonzalez et al. ${ }^{7}$ used satellite images to evaluate the cultivated areas based on a quoted result from the sample lands. DeFries et al., ${ }^{10}$ attributed the percentage of forest land using the regressions technique. Quarmby et al. (1992) used the linear mixing method to get an estimate of region of $2500 \mathrm{~km}^{2}$. Hydrologic basin management involve an enormous area with several resources and necessities; some time ago, satellite images was used in order to get spatial information over specific surface border of heart. However, satellite images have not adequate resolution, atmospheric phenomena and periodicity of sensor have doing difficult the data acquisitions. 
UAV brought response at these disadvantages, aero transporting powerful cameras, or sensors, periodicity and better planning avoiding atmospheric troubles. Several uses have been implemented, for example, in the forest environment, the quantification of the wood volume. Likewise, the creation of new maps has helped understand the relationship between the growth of trees and the factors for its optimal agro-environmental implications. Several ways to estimate the productivity of water have been developed using satellite images by estimating the energy balance in monitoring rain, ${ }^{11}$ observing water surface areas and rivers, ${ }^{4}$ mapping irrigated surface ${ }^{3}$ The potential development of crops is strongly related with the contribution of time and water volume; it is a fact that when an efficient water conduction network is kept, the probabilities to obtain better quality and quantity increases. The goal of this work is to present an offer to supervise the hydrologic regions and management of agricultural infrastructure based in the acquisition of data, images and georeferencing, using UAV with the ending purpose of getting a better idea of the functional characteristics of the hydrologic regions.

\section{UAV uses and advantages}

Water management in a basin involves a compressive distribution of the resource and the application, in order to get equilibrium between source and sink. Lakes, dams and other concentration places is the main source. To obtain data image, the are many possibilities respect the light spectrum. Some infrastructure or specifics traits of the earth surface are possible to observe in the visible range of light. Others traits, for instance, crops characteristics, soil or water may be need different ranges of light, in these cases, infrared, or multispectral cameras will be needed. General procedure for the use of UAV in hydrological zones consist in a planning, execution and post process of image. The use of UAD implies a several steps in order to get useful information to help in the decision support. A general methodology for Hydrologic data acquisition can be described in the follow activities:

a. Identification of the hydrologic basin or region and hydraulic components to flying, dams, irrigation system, bridges, river, etc.

b. Mission autonomous, or free planning over specific hydraulic system

c. Mission execution and data acquisition

d. Download data and post processing of information

e. Analysis of data and results presentation

The procedure can be broken down in stages; in the first stage, the flight for the gathering of data begins, to be able to generate a digital model of the surface with the Unmanned Aerial Device (UAD) technology. Then comes the identification of the infrastructure based on the resolution of the geometrical objects or size of the pixe. ${ }^{3}$ The equipment available can be classified in two big groups: propeller and fix wings. Each one is used in different conditions of fly of time, weigh, etc., but the most important parameters are the sensor in this mobile platform. In this case the drone used, consists of the propeller and fixed wing (Figure 1) with their respective adjuncts for mounting the sensors. For the supervision development, different UAD can be used, for vertical deployment or for vertical landing following the hex copter model (Figure 2) which can be equipped with visible rank sensors and a multi-structural RGB. With the information gathered in each flight, through image treatment using the software adequate, it is intended to use techniques such as the medium size of a pixel and area definitions for:
A. Detection of the physical status of the hydrologic characteristics;

B. Visual surveillance of the hydraulic and irrigation systems and

C. Control of irrigated areas with crops.

In environment sector, there are many alternatives of analysis. Gomez-Candon et al., ${ }^{12}$ described an Object Based Image Analysis (OBIA) which presented more precise images based on pixels, especially when involved with spectral information, as it is the case here. Through this image is possible to determine interest factors such as the start and end of the watercourse. If we add a measure to the approximation, we would be possible to have an estimate of the volume of stored water with planning purposes. Analyzing in spectral format, a body of water is appreciated, which provides information with identified zones with or without vegetation, which is information important in relation to water use. The selection of use of multi spectral or visible images is depending the objective. Monitoring, recognition or measured, and what is measured. In general spectral image allow more rigidity in the data analysis process since there are areas where proper physical observation is not possible, for instance, in the case of a leak or micro-sprinklers, only a spectral image will act as an indicator to evaluate performance rating of the system, through which is possible to infer if the irrigation is efficient by the uniform development of the crops, with respect to other zones and other additional parameters such as the shape and size of the plants or texture parameters of the objects shown in the image. ${ }^{7,13}$
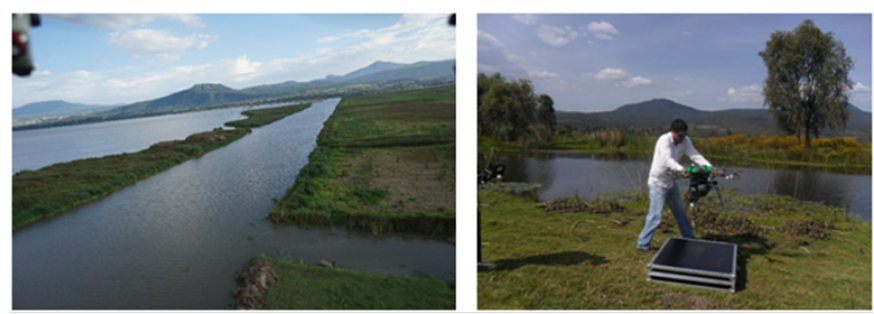

Figure I Inspection in canals of Patzcuaro lake.

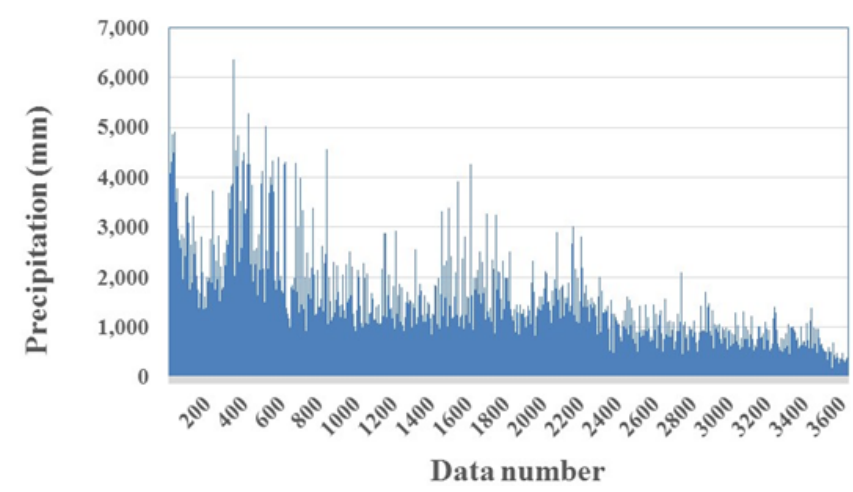

Figure 2 Annual precipitation $(\mathrm{mm})$ variation.

\section{Discussion}

Water volume in the hydrologic basin depends of climate factors but may be precipitation is the most important. Figure 2 show the variation of average annual precipitation in Mexico around the country. Using UAVs is possible to detect even small changes in water surface area, using orthophotomaps like results showed by Niedzielski et al. ${ }^{14}$ As Important than UAV is the sensor autotransporters in the $\mathrm{UAV}$, the RGB camera or visible, and a sufficient overlap to produce 
the dense point cloud is necessary to get an orthophoto. In picture 2, shows the spatial variation of volume useful. Under these condition, was necessary the creation of devices to delivery, conduction and source water. The use of UAVs to transport sensors in one same flight has the ability to generate information (visual, thermic, spectral, etc.) through a post process, increasing the certainty to issue reason concerning the functionality of the hydro agricultural systems; its use is being widely applied in the hydrological field. ${ }^{15-17}$ The geometrical features in irrigation agriculture, such as watercourses, ducts, tubes, etc. provide with useful information concerning the physical status of the hydro agricultural infrastructure. A continued supervision of this storage source, lines of conduction, ducts or tubes and irrigations systems, allows the evaluation of the physical and functional status in which they are found, and as a consequence will help estimate or quote possible losses (Figure 3).
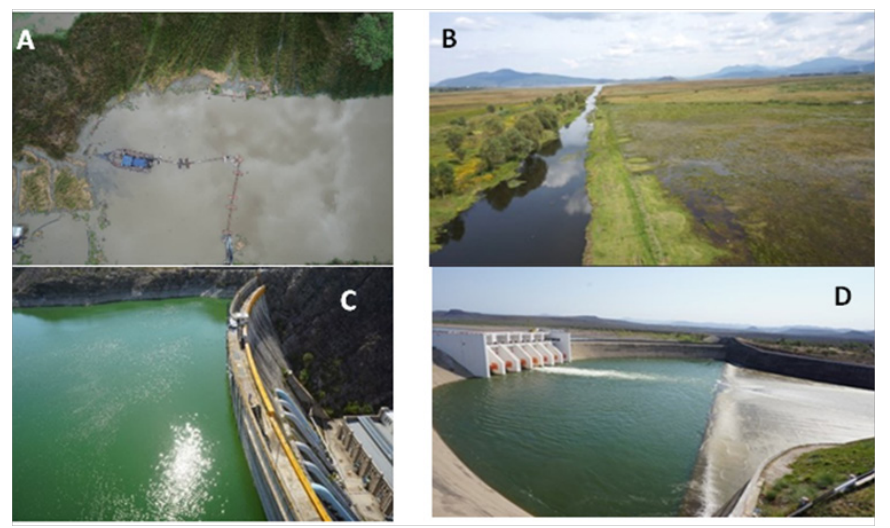

Figure 3 Image of several components of hydrologic basin management and plan. (A) Clean the Patzcuaro lake, Michoacan; (B) Canal operation; (C) The Boquilla Dam, Chihuahua Mex; (D) Spillow Dam Miguel Hidalgo. Sinaloa.

\section{Conclusion}

UAS application in the hydrologic region is a basic activity for the resources planning in the basin. Cameras and sensors aero transported, are an emergent tool to following, monitoring and tele detection of specifics details respect the performance of most of devices in the source, conduction and water application, such as: Dams, Channels, Irrigation systems, etc. Some important advantages of UAVs use, versus satellite images or manual procedures can be grouped in
i. Time of response;
ii. Resolution of the image;
iii. Periodicity of the data acquisition;
iv. Photo Image without cloud or shadows

The geometrical features in agriculture sector, such as dams, watercourses, ducts, tubes, etc. provide with useful information concerning the physical status of the hydrologic basin. A continued tele detection of this storage source, lines of conduction, ducts or tubes and irrigations systems, allows the evaluation of the physical and functional status in which they are found. Spatial and temporal data acquisition of basin, based in sensors aero transported in UAV is a crucial information in the planning of water saving.

\section{Acknowledgements}

None.

\section{Conflict of interest}

The author declare there is no conflict of interest.

\section{References}

1. PNH. Programa nacional hídrico 2007-2012. México: Comisión Nacional del Agua. 2008; p. 158.

2. CONAGUA. Comisión Nacional del Agua. Estadísticas del Agua en México. México: Secretaría de Medio Ambiente y Recursos Naturales. 2010;249.

3. Krishna MG, Prasad ST, Fujii H, et al. Mapping Irrigated Areas of Ghana Using Fusion of $30 \mathrm{~m}$ and $250 \mathrm{~m}$ Resolution Remote-Sensing Data. Remote Sens. 2011;3(4):816-835.

4. Niedzielski T, Matylda W, Waldemar S. Observing river stages using unmanned aerial vehicles. Hydrol Earth Syst Sci. 2016;20:3193-3205.

5. Foody GM, Lucas RM, Curran PJ, et al. Mapping tropical forest fractional cover from coarse spatial resolution remote sensing imagery. Plant Ecology. 1997;131(2):143-154.

6. Gallego FJ, Delince J, Rueda C. Crop area estimates through remote sensing: stability of the regression correction. International Journal of Remote Sensing. 1993;14(18):3433-3445.

7. Castillejo-Gonzalez IL, Lopez-Granados F, Garcia-Ferrer A, et al. Object and pixel based analysis for mapping crops and their agro-envinronmental associated measures usiing Quick Bird Imagenery. Computers and electrnics in Agriculture. 2009;68(2):2017-215.

8. Platonov A, Thenkabail PS, Biradar CM, et al. Water Productivity Mapping (WPM) Using Landsat ETM+ Data for the Irrigated Croplands of the Syrdarya River Basin in Central Asia. Sensors. 2008;8(12):81568180 .

9. Biggs T, Thenkabail PS, Krishna M, et al. Vegetation phenology and irrigated area mapping using combined MODIS time-series, ground surveys, and agricultural census data in Krishna River Basin, India. International Journal of Remote Sensing. 2006;27(19):4245-4266.

10. DeFries R, Hansen M, Steininger M, et al. Subpixel forest cover in Central Africa from Multisensor, multitemporal data. Remote Sensing of Environment. 1997;60(3):226-246.

11. Black E, Tarnavsky E, Maidment R, et al. The Use of Remotely Sensed Rainfall for Managing Drought Risk: A Case Study of Weather Index Insurance in Zambia. Remote Sens. 2016;8(4):342.

12. Gomez-Candon D, De Castro-megias AI, Lopez-granados F. Assesing the acuracy of mosaic from unmanned aerial vehicle (UAV) imagery for precisión agricultura purposes. Precision Agriculture. 2012.

13. Peña-Barragan JM, Ngugi MK, Plant RE, et al. Objec-Based crop identification usin multiple vegetation indices, textural features and crop phenology. Remote sensing and environment. 2011;115(6):1301-1316.

14. Niedzielski T, Miziński B. Stochastic Environmental Research and Risk Assessment Real-time hydrograph modelling in the upper Nysa Kłodzka river basin (SW Poland): a two-model hydrologic ensemble prediction approach. Stochastic Environmental Research and Risk Assessment. 2016.

15. Colomina I, Molina P. Unmanned aerial systems for photogrammetry and remote sensing: A review. ISPRS J Photogramm Remote Sens. 2014;92:79-97.

16. Mi^rijovský J, Langhammer J. Multitemporal Monitoring of the Morphodynamics of a Mid-Mountain Stream Using UAS. Photogrammetry. Remote Sens. 2015;7(7):8586-8609.

17. Ridolfi E, Manciola P. Water Level Measurements from Drones: A Pilot Case Study at a Dam Site. Water. 2018;10(3):297. 